\title{
Screening of Multi-trait Mesorhizobium Isolates for Plant Growth Promotion and Nitrogen Fixation in Chickpea (Cicer arietinum L.)
}

\author{
Pushpa Yadav*, Ramesh Chandra, Navneet Pareek and K.P. Raverkar \\ Department of Soil Science, G. B. Pant University of Agriculture \& Technology, \\ Pantnagar - 263 145, Uttarakhand, India \\ *Corresponding author
}

\section{A B S T R A C T}

\begin{tabular}{|l|}
\hline K e y w o r d s \\
Chickpea, Cicer \\
arietinum L. \\
Mesorhizobium, \\
Nodulation, Plant \\
dry matter, Nitrogen \\
and Phosphorus \\
content, Nitrogen \\
fixation
\end{tabular}

Use of nitrogen fixing and phosphate solubilizing microorganisms (biofertilizers) has become an important aspect of pulse crops production technology. The efficiency of these microorganisms differs widely in accruing the benefits of their application in crops. Ten Mesorhizobium isolates having various plant growth promoting (PGP) traits including phosphate solubilization were screened for their symbiotic efficiency in terms of root nodulation, plant dry matter production, nitrogen and phosphorus content and nitrogen fixation by chickpea plant in a field experiment during 2015-16. The isolates showed considerable variations in the symbiotic performance by producing nodule number from 17.3 to 21.8 plant $^{-1}$, nodule dry weight from 68.0 to $76.1 \mathrm{mg}$ nodule plant ${ }^{-1}$ and plant dry weight from 2.74 to $3.53 \mathrm{~g} \mathrm{plant}^{-1}$ at 60 DAS registering significant increases over the uninoculated control. The shoot and root length at 60 DAS due to inoculation of different isolates also varied significantly and were higher than the uninoculated control. The different isolates accumulated 92.8 to $127.1 \mathrm{mg}$ more nitrogen plant ${ }^{-1}$ indicating fixation of 34.3 to $68.6 \mathrm{mg}$ nitrogen plant $^{-1}$ over the native population at 60 DAS. Mesorhizobium isolate CR-53 was found most promising and followed by the isolates CR-3 and CR-40 in symbiotic performance, nitrogen accumulation and fixation in chickpea. The results suggested that Mesorhizobium isolates having different PGP traits could be a better option for obtaining the benefits of inoculation and improving pulse production.

\section{Introduction}

Chickpea (Cicer arietinum L.) is one of the important grain legumes and cultivated mainly in the Indian subcontinent, Mediterranean region the West Asia and North Africa (WANA) region, and Eastern Africa. India is the largest producer and consumer of chickpea in the world sharing about $71.0 \%$ of the global acreage and production. Chickpea is grown in India on about $8.39 \mathrm{~m}$ ha with annual production of 7.05 metric tons grains and productivity of $889 \mathrm{~kg} \mathrm{ha}^{-1}$. Chickpea grains contain $29 \%$ protein, $59 \%$ carbohydrate, $3 \%$ fibre, $5 \%$ oil and $4 \%$ ash. The protein is rich in lysine and arginine but most deficient in sulphur containing amino acids such as methionine and cysteine (Iqbal et al., 2006). It 
is also a good source of absorbable $\mathrm{Ca}, \mathrm{P}, \mathrm{Mg}$, $\mathrm{Fe}$ and $\mathrm{K}$. Being a leguminous crop, chickpea restores and maintains soil fertility through symbiotic nitrogen fixation in association with Mesorhizobium species in addition to its valuable nutritional quality (Nour et al., 1994). The deep root system and leaf shading habits of chickpea also contributes significantly in improving nutritional and physical health of soil.

Rhizobial populations residing in soils are dynamic and continuously evolving communities. Their diversity stems from the size and plasticity of rhizobial genomes (Black et al., 2012) which enables them to survive in different habitats. Rhizobia often spread from their initial habitats (Stepkowski et al., 2007); however, the success of their introduction into new environments depends upon their ability to adapt in various biotic and abiotic factors (Trotman and Weaver, 1995). The efficiency of the Mesorhizobium sp. strains differ across the locations. Several reports indicated that application of effective Rhizobium inoculants in chickpea results increased crop productivity and soil health (Sahai and Chandra, 2011; Dudeja et al., 2011). Chickpea obtain a significant portion of its nitrogen requirement through symbiotic $\mathrm{N}_{2}$ fixation when grown in association with effective and compatible Rhizobium strains. Recently, rhizobia have been shown to promote the plant growth through PGP mechanisms that are different from the atmospheric $\mathrm{N}_{2}$ fixation. PGP traits such as secretion of phyto-hormones like indole acetic acid that enhances plant growth, synthesis of the enzyme 1aminocyclopropane-1-carboxylate (ACC) deaminase, which can lower plant ethylene levels, solubilization of minerals such as phosphorus making it more readily available for plant growth, siderophore production that can sequester iron from the soil and provide it to plant cells and by conferring increased resistance against plant pathogens have been reported (Antoun et al., 1998; Deshwal et al., 2003). The present study was conducted to compare the performance of different Mesorhizobium isolates having PGP traits for plant growth promotion and nitrogen fixation in chickpea under field conditions.

\section{Materials and Methods}

The screening of the 10 different multi-trait mesorhizobial isolates having PGP traits $(\mathrm{P}$ solubilization, IAA, GA, Siderophore and $\mathrm{HCN}$ production) was done in a field experiment at Pantnagar at Norman E. Borlaug Crop Research Centre of the University $\left(29^{\circ} \mathrm{N}\right.$ latitude, $79.3^{\circ} \mathrm{E}$ longitude and at an altitude of $243.8 \mathrm{~m}$ above the mean sea level) during Rabi season of 2016 to 2017. The experimental soil was Sandy loam of $\mathrm{pH}$ 6.90 and EC $0.24 \mathrm{dSm}^{-1}$ having $0.67 \%$ Organic C and 180.2, 20.1 and $261.4 \mathrm{~kg} \mathrm{ha}^{-1}$ available $\mathrm{N}, \mathrm{P}$ and $\mathrm{K}$, respectively. Treatments consisting seed inoculation with 10 mesorhiobial isolates (CR-3, CR-11, CR-21, CR-25, CR-40, CR-41, CR-46, CR-47, CR-53 and CR-62) with an uninoculated control and RDF (20 kg N ha $\left.{ }^{-1}+40 \mathrm{~kg} \mathrm{P}_{2} \mathrm{O}_{5} \mathrm{ha}^{-1}\right)$ were laid out in plots of $3.0 \mathrm{~m} \times 4.0 \mathrm{~m}$ size following randomized block design with 3 replications.

The Chickpea (cv. PG-186) was sown on $23^{\text {rd }}$ November 2016 with a seed rate of $100 \mathrm{~kg}$ ha

1 . Seeds were surface sterilized by soaking in $0.1 \% \mathrm{HgCl}_{2}$ for 2 minutes and then thoroughly washed with sterilized distilled water. The inoculums of each Mesorhizobium isolate were prepared by multiplying in YEM broth for 4 days. Seeds were treated with the inoculums of different Mesorhizobium isolates separately by mixing with $4 \mathrm{ml}$ inoculum $\mathrm{kg}^{-1}$ seed at the time of sowing. Then treated seeds were sown immediately in tractor opened furrows at 3-4 $\mathrm{cm}$ depth. Nitrogen $\left(20 \mathrm{~kg} \mathrm{ha}^{-1}\right)$ and phosphorous (40 kg $\mathrm{P}_{2} \mathrm{O}_{5} \mathrm{ha}^{-1}$ ) were applied as per treatment through urea and single super phosphate, respectively. 
Recommended dose of Potassium (20 kg ha ${ }^{-1}$ ) was given uniformly to all plots through muriate of potash. All the fertilizers were applied in planting furrows prior to seed showing. The crop was raised and protected from insects, pests and diseases as per the standard recommended practices.

Five plants from each plot were randomly uprooted from the side rows along with a soil block of about $25 \mathrm{~cm}$ diameter at 60 days after sowing (DAS). Adhered soil with roots was washed off with tap water carefully by keeping the roots of plants in sieve. Nodules were removed from the roots; counted and their dry weight was recorded after drying in hot air oven to constant weight at $65^{\circ} \mathrm{C}$. The shoot and root lengths of the uprooted plants from each plot was also recorded. The plants were then dried at $65^{\circ} \mathrm{C}$ to constant weight and their dry weights were recorded. The $\mathrm{N}$ in finely grinded (40 mesh) plant sample was estimated using rapid $\mathrm{N}$-cube analyzer (Elementar) and nitrogen accumulation in plants was computed by multiplying with the plant dry weight. The concentration of phosphorous in chickpea plants at 60 DAS was estimated by molybdovandate phosphoric acid yellow colour method after wet digestion in di-acid $\left(\mathrm{HNO}_{3}: \mathrm{HCLO}_{4}, 9: 4\right)$ (Page, 1982). The obtained experimental data were subjected to statistical analysis appropriate to the design by STPR3 software of G.B.P.U.A. $\&$ T Pantnagar. The treatments difference was tested by using F-test of significance at 5\% level of probability (Panse and Suchatme, 1978).

\section{Results and Discussion}

\section{Nodule number}

Inoculation of different Mesorhizobial isolates influenced the root nodule number significantly at 60 DAS (Table 1). Nodule number plant $^{-1}$ due to different treatments ranged from 14.9 to 21.8. All the Mesorhizobium isolates, except CR-11 and CR-21, gave significantly higher nodule number, by 22.1 to $46.3 \%$, over the uninoculated control and was followed by CR3 and CR-40 in nodule number. Mesorhizobium isolate CR-53 recorded significantly more nodule number than CR-11, CR-21 and CR-46 and was at par with remaining isolates. Isolates CR-53, CR-3 and CR-40 also produced significantly more nodule number than application of $20 \mathrm{~kg}$ $\mathrm{N}+40 \mathrm{~kg} \mathrm{P}_{2} \mathrm{O}_{5} \mathrm{ha}^{-1}$ of $48.2,43.4$ and $41.0 \%$, respectively. These results are in agreement with the earlier report of Gupta (2006) and Bhatt and Chandra (2014) who similarly reported significant increases in nodule number in chickpea due to Mesorhizobium inoculation in field conditions. The significant and variable effects of inoculated Mesorhizobium isolates may be attributed to better survival of the inoculated Mesorhizobium isolates in soil to cause infection for nodule development.

\section{Nodule dry weight}

Root nodule dry weight at 60 DAS due to different Mesorhizobium sp. isolates, except CR-21 and CR-11, was significantly more than the uninoculated control. The highest nodule dry weight was recorded with isolates CR-53 followed by CR-40 and CR-3 registering 26.4, 25.6 and $24.8 \%$ significant increases over the uninoculated control. Although, all the isolates were at par, but isolates CR-53, CR-3, CR-25 and CR-40 were observed more effective than others by registering significant increases in nodule dry weight over the application of $20 \mathrm{~kg} \mathrm{~N}+40 \mathrm{~kg}$ $\mathrm{P}_{2} \mathrm{O}_{5}$ ha $^{-1}$. Such beneficial effects of Mesorhizobium inoculation in chickpea have also been reported by Kaur et al (2015) due to enhancement in nodule number and synthesis of more nodule tissue because of presence of other PGP traits such as P solubilization, 
siderophores production, IAA production etc.

\section{Shoot length}

Shoot length of chickpea plants at 60 DAS ranged between 24.4 to $31.6 \mathrm{~cm}$. Application of $\mathrm{RDF}\left(20 \mathrm{~kg} \quad \mathrm{~N}+40 \mathrm{~kg} \quad \mathrm{P}_{2} \mathrm{O}_{5} \quad \mathrm{ha}^{-1}\right)$ was statistically comparable the uninoculated control, while inoculation of different Mesorhizobium isolates significantly increased the shoot length ranging from 12.3 to $29.3 \%$ (Table 1). The highest shoot length was recorded with isolate CR-53 followed by isolates CR-3, CR-40, CR-25 and CR-47 registering significant increments of 29.3, $28.0,28.0,24.7$ and $18.4 \%$ over the uninoculated control, respectively. Isolates CR-53, CR-3, CR-40 and CR-25 were also found significantly superior to $20 \mathrm{~kg} \mathrm{~N}+40 \mathrm{~kg}$ $\mathrm{P}_{2} \mathrm{O}_{5} \mathrm{ha}^{-1}$ treatment by recording $21.8,20.5$, 20.5 and $17.4 \%$ more shoot length at 60 DAS. This could be viewed in the light of superiority of these isolates than others in root nodulation, which resulted in higher nitrogen fixation and plant growth. Mabrouk and Belhadj (2014) found that inoculation of chickpea by different Rhizobium strains showed significant differences in dry matter at 45 DAS and shoot growth was significantly increased by two fold when the chickpea plants were inoculated with Rhizobium isolates Pch. Azm and Pch. Bj1 as compared to the uninoculated control.

\section{Root length}

Alike shoot length, chickpea root length due to inoculation of different Mesorhizobium isolates was higher, by 14.9 to $28.4 \%$, over the uninoculated control (Table 1). All the isolates, except CR-11 and CR-21 were statistically comparable in root length. The highest root length was recorded with isolate CR-53 followed by CR-3, CR-40 and CR-41 registering significant increases of 44.8, 43.0, 41.4 and $34.4 \%$ over the uninoculated control, respectively. These isolates also showed significant increases in root length of 30.8 , $29.2,27.4$ and $21.4 \%$ over the application of $20 \mathrm{~kg} \quad \mathrm{~N}+40 \mathrm{~kg} \quad \mathrm{P}_{2} \mathrm{O}_{5} \quad \mathrm{ha}^{-1}$, respectively suggesting variable influence of the isolates on root length and could be attributed to occurrence of PGP traits in the isolates. Similarly finding was also reported by Lal and Khan, (2014).

\section{Plant dry weight}

Application of $20 \mathrm{~kg} \mathrm{~N}+40 \mathrm{~kg} \mathrm{P}_{2} \mathrm{O}_{5}$ ha $^{-1}$ gave numerical increase in plant dry weight of $20.8 \%$ over the uninoculated control (Table 1). Inoculation of different Mesorhizobium sp. isolates showed significant increases in plant dry weight ranging from 49.7 to $92.9 \%$ over uninoculated control. The highest plant dry weight was recorded with isolate CR-53 registering $92.9 \%$ higher plant dry weight than the uninocualted control. It was followed by CR-3, CR-40 and CR-25 registering significant increases of 84.7, 83.6 and $81.4 \%$ over uninoculated control, respectively.

Isolate CR-53 was at par with CR-3, CR-40 and CR-41 and significantly superior to all other isolates in plant dry weight. All isolates were also found to be significantly better than application of $20 \mathrm{~kg} \mathrm{~N}+40 \mathrm{~kg} \mathrm{P}_{2} \mathrm{O}_{5} \mathrm{ha}^{-1}$. Malik and Sindhu (2011) also reported that inoculation of chickpea seed with Mesorhizobium sp. alone increased the plant dry weight that varied from 1.14 to 1.80 times in comparison to uninoculated control. Biologically fixed nitrogen is the most dominating factor influencing the dry weight of shoot (Fatima et al., 2008). Increase in dry weight of shoot compared to uninoculated control was also reported by Akthar and Siddiqui (2009).

\section{Nitrogen and Phosphorus content in plant}

Nitrogen and Phosphorus content in plants due to application of $20 \mathrm{~kg} \mathrm{~N}+40 \mathrm{~kg} \mathrm{P}_{2} \mathrm{O}_{5}$ ha $^{-1}$ was comparable to the uninoculated control (Table 2). 
Table.1 Inoculation effect of Mesorhizobium isolates on nodulation, plant growth and dry matter production at $60 \mathrm{DAS}$

\begin{tabular}{|c|c|c|c|c|c|}
\hline Treatment & $\begin{array}{c}\text { Nodule } \\
\text { number } \\
\text { plant }^{-1}\end{array}$ & $\begin{array}{c}\text { Nodule dry } \\
\text { weight } \\
\text { plant }^{-1}\end{array}$ & $\begin{array}{c}\text { Shoot } \\
\text { length } \\
\text { (cm) }\end{array}$ & $\begin{array}{c}\text { Root } \\
\text { length } \\
(\mathbf{c m})\end{array}$ & $\begin{array}{c}\text { Plant dry } \\
\text { weight } \\
\left.\text { (g plant }^{-1}\right)\end{array}$ \\
\hline Uninoculated control & 14.9 & 60.2 & 24.43 & 9.60 & 1.83 \\
\hline${ }_{1}^{20 k g ~ N+40 k g ~} \mathrm{P}_{2} \mathrm{O}_{5} \mathrm{ha}^{-}$ & 16.2 & 64.5 & 25.90 & 10.63 & 2.21 \\
\hline CR-3 & 21.0 & 75.1 & 31.27 & 13.73 & 3.38 \\
\hline CR-11 & 17.3 & 68.0 & 27.43 & 11.03 & 2.74 \\
\hline CR-21 & 17.3 & 67.9 & 27.93 & 11.77 & 2.77 \\
\hline CR-25 & 19.3 & 73.8 & 30.47 & 12.80 & 3.32 \\
\hline CR-40 & 20.0 & 75.6 & 31.27 & 13.57 & 3.36 \\
\hline CR-41 & 19.2 & 73.9 & 30.10 & 12.90 & 3.22 \\
\hline CR-46 & 18.2 & 72.5 & 28.67 & 12.13 & 2.87 \\
\hline CR-47 & 18.8 & 72.9 & 28.93 & 12.33 & 2.94 \\
\hline CR-53 & 21.8 & 76.1 & 31.60 & 13.90 & 3.53 \\
\hline CR-62 & 18.8 & 72.1 & 29.17 & 12.37 & 3.03 \\
\hline CD at $5 \%$ & 3.1 & 9.1 & 4.27 & 1.82 & 0.41 \\
\hline
\end{tabular}

Table.2 Inoculation effect of Mesorhizobium isolates on nitrogen and phosphorus concentrations and nitrogen fixation by chickpea plant at 60 DAS

\begin{tabular}{|c|c|c|c|c|c|}
\hline Treatment & $\begin{array}{c}\text { Nitrogen } \\
\text { content } \\
(\%)\end{array}$ & $\begin{array}{l}\text { Phosphorus } \\
\text { content (\%) }\end{array}$ & $\begin{array}{c}\text { Nitrogen } \\
\text { accumulation } \\
\left(\text { mg plant }^{-1}\right)\end{array}$ & $\begin{array}{c}\text { Nitrogen } \\
\text { fixed over } \\
\text { control } \\
\left(\mathrm{mg} \mathrm{plant}^{-1}\right)\end{array}$ & $\begin{array}{l}\text { Nitrogen fixed } \\
\text { overFertilizer } \\
\text { treatment (mg } \\
\left.\text { plant }^{-1}\right)\end{array}$ \\
\hline Uninoculated control & 3.202 & 0.198 & 58.5 & - & - \\
\hline${ }_{1}^{20} \mathrm{~kg} \mathrm{~N}+40 \mathrm{~kg} \mathrm{P}_{2} \mathrm{O}_{5} \mathrm{ha}^{-}$ & 3.308 & 0.207 & 72.7 & - & - \\
\hline CR-3 & 3.595 & 0.217 & 121.5 & 63 & 48.8 \\
\hline CR-11 & 3.376 & 0.208 & 92.8 & 34.3 & 20.1 \\
\hline CR-21 & 3.440 & 0.211 & 95.3 & 36.8 & 22.6 \\
\hline CR-25 & 3.545 & 0.213 & 117.9 & 59.4 & 45.2 \\
\hline CR-40 & 3.571 & 0.216 & 119.8 & 61.3 & 47.1 \\
\hline CR-41 & 3.527 & 0.212 & 113.4 & 54.9 & 40.7 \\
\hline CR-46 & 3.450 & 0.211 & 99.2 & 40.7 & 26.5 \\
\hline CR-47 & 3.470 & 0.212 & 102.0 & 43.5 & 29.3 \\
\hline CR-53 & 3.597 & 0.219 & 127.1 & 68.6 & 54.4 \\
\hline CR-62 & 3.481 & 0.212 & 105.3 & 46.8 & 32.6 \\
\hline CD at $5 \%$ & 0.361 & NS & 20.0 & - & - \\
\hline
\end{tabular}


However, inoculation of different Mesorhizobium isolates increased the plant nitrogen content ranging from 5.4 to $12.3 \%$ and phosphorous content from 5.1 to $10.6 \%$ over the uninoculated control. Isolate CR-53 showed highest nitrogen and phosphorus content and was followed by isolates CR-3 and CR-40 registering significant increases of $12.3,12.3$ and $11.5 \%$ in plant nitrogen content and 10.6, 9.6, 9.1 in plant phosphorous content over the uninoculated control, respectively. These isolates gave statistically comparable nitrogen and phosphorus contents in plant. These results are in agreement with the earlier reports of Sarna et al (2008) and Qureshi et al (2009) and may be due to increased nitrogen fixation and phosphorus solubilization in soil leading to increased availability for plants. The variations in the ability of nitrogen fixation and phosophorus solubilization by rhizobia have also been reported elsewhere (Dudeja et al., 2011).

\section{Nitrogen fixation}

Nitrogen fixation by different Mesorhizobium isolates was computed over the indigenous population by difference method. The different isolates accumulated 92.8 to 127.1 $\mathrm{mg}$ plant ${ }^{-1}$ more nitrogen indicating fixation of 34.3 to $68.6 \mathrm{mg}$ plant $^{-1}$ over the native population under uninocualted control treatment (Table 2). The highest nitrogen accumulation was obtained with isolate CR53 followed by CR-3 and CR-40. These isolates fixed $68.6,63.0$ and $61.3 \mathrm{mg}$ plant $^{-1}$ more nitrogen over the uninocualted control and 54.4., 48.8 and $47.1 \mathrm{mg}$ plant $^{-1}$ more nitrogen over application of $20 \mathrm{~kg} \mathrm{~N}+40 \mathrm{~kg}$ $\mathrm{P}_{2} \mathrm{O}_{5} \mathrm{ha}^{-1}$, respectively and were superior to remaining isolates. The fertilizer treatment recorded slightly more nitrogen over the uninoculated control. Nitrogen fixation efficiency is dependent on genetic makeup of the rhizobia and also influenced by soil and environmental factors. Similar variations in the nitrogen fixation efficiency of the rhizobia have been reported by Sarr et al. (2016). The Mesorhizobium isolates were obtained from diverse locations and it is expected that they differ in their efficiency in establishing the symbiosis and subsequently nitrogen fixation. In conclusion, results of the study clearly demonstrated the variations in the symbiotic efficiency of the Mesorhizobium isolates. Isolate CR-53, CR-3 and CR-40 were found promising in enhancing the rootnodulation, dry weight matter production and nitrogen fixation in chickpea. The further studies are needed to confirm the findings under different agro-ecological situations.

\section{References}

Akhtar, M. S. and Siddiqui, Z. A. 2009. Effects of phosphate solubilizing microorganisms and Rhizobium sp. on the growth, nodulation, yield and rootrot disease complex of chickpea under field condition. Afr. J. Biotechnol. 8(15): 3489-3496.

Antoun, H., Beauchamp, C.J., Goussard, N., Chabot, R. and Lalande, R. 1998. Potential of Rhizobium and Bradyrhizobium species as plant growth promoting rhizobacteria on nonlegumes: effect on radishes (Raphanus sativus L.). Plant and Soil. 204, 57-67.

Bhatt, Parul. and Chandra, R. 2014. Inoculation effect of Mesorhizobium ciceri and rhizospheric bacteria on nodulation and productivity of chickpea (Cicer areietinum L.) and soil health. Int. J. Basic and Appl. Agricu. Res. 12(1): 59-64.

Black, M., Moolhuijzen, P., Chapman, B., Barrero, R., Howieson, J., Hungria, M., and Bellgard, M. 2012. The genetics of symbiotic nitrogen fixation: comparative genomics of 14 rhizobia strains by resolution of 
protein clusters. Genes. 3, 138-166.

Deshwal, V.K., Dubey, R.C. and Maheshwari, D.K. 2003. Isolation of plant-growth promoting strains of Bradyrhizobium (Arachis) sp. with biocontrol potential against Macrophomina phaseolina causing charcoal rot of peanut. Curr. Sci. 84, 443-448.

Dudeja, S. S., Singh, N. P., Poonam Sharma, Gupta, S.C., Ramesh Chandra, Bansi Dhar, Bansal, R.K, Brahmaprakash, G.P., Potdukhe, S.R., Gundappagol, R.C., Gaikawad, B.G. and Nagaraj, K.S. 2011. Biofertilizer Technology and Pulse Production. In: Bioaugmentation, Biostimulation and Biocontrol. (A. Singh et al. Eds.), Springer-Verlag Berlin Heidelberg, pp 43-63.

Fatima, Z., Bano, A., Sial, R. and Aslam, M. 2008. Response of chickpea to plant growth regulators on nitrogen fixation and yield. Pak. J. Bot. 40, 2005-2013.

Gupta, S. C. 2006. Effect combined inoculation on nodulation nutrient uptake and yield of chickpea in Vertisol. J. Indian Soc. Soil Sci. 54, 251-254.

Iqbal, A., Ateeq, N., Khalil, I.A., Perveen, S. and Saleemullah, S. 2006. Physicochemical characteristics and amino acid profile of chickpea cultivars grown in Pakistan. J. Foodservice. 17(2):94-101.

Kaur, N., Sharma, P., and Sharma, S., 2015. Co-inoculation of Mesorhizobium sp. and plant growth promoting rhizobacteria Pseudomonas sp. as bioenhancer and bio-fertilizer in chickpea (Cicer arietinum L.). Legume Res. 38 (3): 367-374.

Lal, N. and Khan, Z.H. 2014. Effects of Rhizobium Inoculation on in vitro Germination and in vivo Nodulation and Early Plant Growth in Black gram and Green gram. J. Funct. and
Environ. Bot. 4(1): 37-40.

Mabrouk, Y. and Belhadj, O. 2014. Effect of the inoculation of chickpea by rhizobia on growth promotion and protection against Orobanche Crenata. G.J.B.A.H.S. 3(3): 55-59.

Malik, D. K. and Sindhu, S. S. 2011. Production of indole acetic acid by Pseudomonas sp.: Effect of coinoculation with Mesorhizobium sp. Cicer on nodulation and plant growth of chickpea (Cicer arietinum). Physiol. Mol. Biol. Plants. 17: 25-32.

Nour, S., Fernandez, M. P., Normand, P. and Cleyt- Marely, G. C. 1994. Rhizobium ciceri sp. Nov. consisting of strains that nodulate chickpea. Int. J. of Sys. Bact. 44, 511-522.

Page, A.L. 1982. Methods of soil analysis. Part 2, Chemical and microbiological properties. $2^{\text {nd }}$ ed. Madison(WI), ASA and SSSA.

Panse, V.G. and Sukhatme, P.V. 1978. Statistical methods for Agricultural workers. I.C.A.R., New Delhi.

Qureshi, M. A., Ahmad, Naveed, M., Iqbal, A., Akhtar, N., Niazi, K.H. 2009. Coinoculation with Mesorhizobium ciceri and Azotobacter chroococcum for improving growth, nodulation and yield of chickpea (Cicer arietinum L.). Soil Environ. 28, 124-129.

Sahai, P. and Chandra, R. 2011. Performance of Liquid and Carrier based Inoculants of Mesorhizobium ciceri and PGPR (Pseudomonas diminuta) in Chickpea (Cicer arietinum L.) on Nodulation, Yield and Soil properties. J. Indian Soc. Soil Sci. 59 (3): 263-267.

Sarna, S., Sharma, P., Khurana, A. S. 2008. Combined inoculation of Azotobacter and plant growth promoting rhizobacteria on the efficiency of Rhizobium in chickpea. Ann. Pl. Soil. Res. 10, 39-43.

Sarr, P. S., Okon, J. W., Begoude,D.A. B., 
Araki, S., Ambang, Z., Shibata, M. and Shinya Funakawa, S. 2016. Symbiotic $\mathrm{N}_{2}$-fixation estimated by the ${ }^{15} \mathrm{~N}$ tracer technique and growth of Pueraria phaseoloides (Roxb.) Benth. inoculated with Bradyrhizobium strain in field conditions. Hindawi Publishing Corporation Scientifica. 2016, 1- 10.

Stępkowski, T., Hughes, C. E., Law, I. J.,
Markiewicz, L., Gurda, D., Chlebicka, A. and Moulin, L. 2007. Diversification of lupine Bradyrhizobium strains: evidence from nodulation gene trees. Appl. Environ. Microbiol. 73, 3254-3264.

Trotman, A. P. and Weaver, R.W. 1995. Tolerance of clover rhizobia to heat and desiccation stresses in soil. Soil Sci. Soc. Am. J. 59, 466-470.

\section{How to cite this article:}

Pushpa Yadav, Ramesh Chandra, Navneet Pareek and Raverkar, K.P. 2018. Screening of Multi-trait Mesorhizobium Isolates for Plant Growth Promotion and Nitrogen Fixation in Chickpea (Cicer arietinum L.). Int.J.Curr.Microbiol.App.Sci. 7(08): 2592-2599.

doi: https://doi.org/10.20546/ijcmas.2018.708.266 